\title{
Direct to you: innovative information services to support nurses' continuing competence in Manitoba ${ }^{1}$
}

\author{
Lisa Demczuk, Analyn Cohen Baker, Christine Shaw-Daigle, and Melissa Raynard
}

\section{Introduction}

The libraries in Winnipeg, Manitoba, community hospitals identified an ideal opportunity to develop new programs and services to reach practicing nurses in their own setting. In 2004, the College of Registered Nurses of Manitoba (CRNM) began the implementation of a Continuing Competence Program that requires nurses to annually demonstrate, as part of their registration renewal, a commitment to life-long learning, and their participation in professional development activities [1]. The libraries recognized that many nurses, because of the time constraints of clinical responsibilities, shift work, and family life, have difficulties visiting the physical library in person to find resources to support learning and selfdevelopment. To bring relevant information directly to the nurses to support their continuing competence information needs, the librarians of the Winnipeg community hospitals developed four innovative onsite and virtual library programs and services.

\section{Background and setting}

Registered nurses across Canada are part of the competency movement aimed at increasing the professionalism, accountability, and self-regulation of the nursing workforce [2]. The Canadian Nurses Association, in a joint statement

L. Demczuk. ${ }^{1}$ Bill Larson Library, Grace Hospital, University of Manitoba, 300 Booth Drive, Winnipeg, MB R3J 3M7, Canada.

A. Cohen Baker. Seven Oaks General Hospital Library, University of Manitoba, 2300 McPhillips Street, Winnipeg, MB R2V 3M3, Canada.

C. Shaw-Daigle. Victoria General Hospital Library, University of Manitoba, 2340 Pembina Highway, Winnipeg, MB R3T 2E8, Canada.

M. Raynard. Concordia Hospital Library, University of Manitoba, 1095 Concordia Avenue, Winnipeg, MB R2K 3S8, Canada.

${ }^{1}$ This article is based on a poster presented at the Canadian Health Libraries Association Conference, 14 May 2006, Vancouver, B.C.

${ }^{2}$ Corresponding author (e-mail: lisa_demczuk@umanitoba.ca). with the Canadian Association of Schools of Nursing, describes continuing competence as "the ongoing ability of a nurse to integrate and apply the knowledge, skills, judgement, and personal attributes required to practice safely and ethically in a designated role and setting". The individual nurse is "responsible for demonstrating commitment to continuing competence through life-long learning, reflective practice, and integrating learning into nursing practice" [3].

The province of Manitoba followed the trend of the other provinces and territories and adopted many of the principles of continuing competency programs as laid out in $\mathrm{A} \mathrm{Na}$ tional Framework for Continuing Competence Programs for Registered Nurses [4]. Beginning in 2004, the Continuing Competence Program has been administered through the CRNM as part of nurses' annual registration renewal. This is a substantial departure from the past practice that required the annual documentation of only nursing practice hours to demonstrate continuing competence [5]. The new program focuses on the maintenance and enhancement of competence throughout a nurse's career. The foundation of the program is life-long learning and reflective practice or self-assessment. Rather than require the completion of formal continuing education units, nurses practicing in Manitoba must document self-assessment of their current practice and provide a selfdevelopment plan that includes evidence of professional development learning activities [6]. The possible activities that nurses can engage in cover a broad scope. Some of the activities suggested by the CRNM are the following: borrowing journals, books, or articles from the facility library; conducting literature reviews; participating in a journal club; attending conferences, seminars, workshops, and in-services [7].

The libraries of the Winnipeg community hospitals are units of the University of Manitoba Neil John Maclean Health Sciences Library. The libraries are located in the Concordia Hospital, Grace Hospital, Seven Oaks General Hospital, and the Victoria General Hospital and were organized through an affiliation agreement with the Winnipeg Regional Health Authority (WRHA) and the University of Manitoba (UM). This agreement enabled the hospital libraries to access the print and electronic resources of the University of Manitoba Libraries (UML) system and maintain Web 
sites as part of the UML Web pages. The health care professionals of the community hospitals and the WRHA (including more than 7000 nurses) are all eligible to receive library and information services and have benefited by the expansion of access to health databases, electronic journals, and e-books through the UML.

\section{Program description}

The programs and services introduced by the community hospital libraries were intentionally developed and delivered to both support the registered nurses in their continuing competency requirement to demonstrate and document professional development activities and to make it as easy as possible for the nurses to get that information. The four programs and services are webliographies hosted on the UML Web pages; Competency Collection Information Pathfinder; On the Unit; and Info-RN: a newsletter for nurses.

Webliographies are like roadmaps, convenient routes to information sources on selected topics. The webliographies are online resource guides to books held in the UM libraries, journal articles, and reputable Web sites. Each webliography (there are now 30) is created and regularly updated by individual librarians. The topics are chosen and the webliography developed with input from nurses in response to nurses' information needs. The webliographies are presented in an alphabetical title list that links to the full resource and are easy to access from the UML Web pages (http://umanitoba.ca/ libraries/units/health/links/webliographies.html). The webliographies are also designed to easily connect the listed information to the full source. Each book title is linked to BISON, the UML catalogue, allowing a nurse to request a specific title, have it delivered and held at the hospital library of his or her choosing. The library can then have the book delivered right to the nurse's unit. Each article citation listed in the webliography is embedded with a UM Links icon that, depending on licensing restrictions, provides the SFX link to any available full text of the article, to the UML catalogue for a search of a print holding of the journal, and to a document delivery request form that lets the nurse request a copy of the article from his or her hospital library.

For nurses who are not yet ready to access information in the online environment, the Competency Collection Information Pathfinder is a customized package of print information that is put right in the nurse's hands. Each folder includes multiple copies of a current bibliography of books and articles on a specific topic. One copy of selected articles and book chapters, along with information on how to request further articles and the complete books, is provided in the package. The Competency Collection is placed in a convenient location in the nursing ward or unit. It can be used for self-study, and the bibliography list makes it easy for the nurse to note what has been read and include the proper citation for documentation of continuing education. The collection is easily produced and customized for specific units based on their direct clinical care issues and expressed need for information.

The Competency Collection is an effective, although passive, means of bringing clinical and continuing education information to nurses. The On the Unit service is a more active method of connecting with the nurses. In this service, the community hospital librarians make regular visits (biweekly or monthly) to selected units within the hospital. These visits, usually lasting $1 \mathrm{~h}$, take place at a time most suited to the constraints of the unit's work flow and afford the majority of nurses the opportunity to take advantage of the service. The librarian brings a variety of resources "on the unit" - new books, recent journal issues, and a selection of printed articles - all of which can be immediately borrowed by nurses. The librarian also answers questions, takes requests for literature searches, demonstrates Web pages and information retrieval techniques, and markets library services. Not only does the On the Unit service provide another access point to the library resources, but it has enabled nurses to put a face to the library, thereby increasing their comfort level with seeking information.

The final new service, Info-RN: a newsletter for nurses, is a specially designed electronic newsletter that highlights nursing resources, both print and Internet-based, and library services that are targeted towards nurses. Produced three times per year, the newsletter is posted to the Web pages of the community hospital libraries and the Neil John Maclean Health Sciences Library (http://www.umanitoba.ca/libraries/ units/health/newsletter/index.html) and is distributed via email to the hospital nurses and University of Manitoba Faculty of Nursing staff and students. The format of the newsletter permits direct linking, as allowed by license restrictions, to any featured electronic resources or Web sites. New books and audio-visual materials that are reviewed are also linked within the newsletter to their catalogue record, allowing nurses to request these items directly from the newsletter. This low-cost, easily distributed publication has been well received by nurses, many of whom have suggested topics for future issues.

\section{Outcomes and discussion}

The hospital libraries have received a positive response to the new program and service initiatives. Each of these initiatives, the webliographies, Competency Collection, On the Unit, and Info-RN, have succeeded in bringing authoritative information directly to nurses. Each initiative addresses the particular information needs of nurses working on the wards or units of the Winnipeg community hospitals. The benefits of these varied information programs and services are reflected in several ways. First, in spite of their hectic ward work, nurses are provided with literature and resources that they can read, critically reflect upon, and directly cite as evidence of learning activities undertaken to meet their individual self-development plans. Second, many of the webliographies, Competency Collection resources, and Info-RN features have direct clinical applications for nurses in their patient care, planning, and administration. Third, essential library research and information literacy skills are being communicated to nurses. This directly supports the CRNM competency goal of nurses that embraces the principles of life-long learning. This has been achieved during the On the Unit librarian visits and in the Info-RN newsletter, which has included features on searching PubMed, using the UML catalogue to search for and request titles, creating citation lists and bibliographies with RefWorks, evaluating health sites on the Web, and so forth. Any nurse who wishes more in-depth instruc- 
tion can request an individual tutorial with a librarian and receive a participation certificate of the session, suitable for documenting the learning activity.

The new program and service initiatives have been beneficial for the community hospital libraries as well as the nurses. The libraries have shown themselves to be an invaluable resource by reaching out to support nurses as they undertake their new continuing competence requirements. The nurses in the community hospitals have become familiar with the libraries and the resources and services. As well as being recipients of the information delivered directly to them, the nurses are becoming more active in approaching the library themselves. The new role for nurses in Manitoba, in adopting the principle of life-long learning and demonstrating professional development learning activities, has also meant a new role for the hospital libraries of the Winnipeg community hospitals.

\section{References}

1. College of Registered Nurses of Manitoba. Continuing Competence Program Handbook. Winnipeg, Man.: College of Registered Nurses of Manitoba; 2004.
2. Nelson S, Purkis ME. Mandatory reflection: the Canadian reconstitution of the competent nurse. Nurs Inq. 2004;11(4):247-57.

3. Canadian Nurses Association, Canadian Association of Schools of Nursing. Joint Position Statement. Promoting continuing competence for registered nurses. Ottawa, Ont.: Canadian Nurses Association; 2004.

4. Canadian Nurses Association. A national framework for continuing competence programs for registered nurses. Ottawa, Ont.: Canadian Nurses Association; 2000.

5. College of Registered Nurses of Manitoba. Continuing Competence Program Handbook. Winnipeg, Man.: College of Registered Nurses of Manitoba; 2004.

6. College of Registered Nurses of Manitoba. Continuing competence frequently asked questions. Manit RN J. 2004;29(2):38-9.

7. College of Registered Nurses of Manitoba. Continuing Competence Program Pocket Journal. Winnipeg, Man.: College of Registered Nurses of Manitoba; 2004. 